\title{
Micro- and macro-porosity of dry- and saturated- state recycled aggregate concrete
}

\author{
Thomas, C. ${ }^{* 1}$; Setién, J. ${ }^{\text {; }}$ Polanco, J.A. ${ }^{1}$; de Brito, J.2; Fiol, F. ${ }^{3}$ \\ 1 LADICIM (Laboratory of Materials Science and Engineering), University of Cantabria. E.T.S. de \\ Ingenieros de Caminos, Canales y Puertos, Av. Los Castros 44, 39005 Santander, Spain \\ 2 Instituto Superior Técnico, Universidade de Lisboa, Av. Rovisco Pais, 1049-001 Lisbon, Portugal \\ 3 Department of Construction, University of Burgos. EPS, Calle Villadiego s/n, Burgos, Spain \\ * Corresponding author: carlos.thomas@unican.es
}

\begin{abstract}
Society is becoming aware of the environment and progressively using more recycled aggregates to produce recycled structural aggregate concrete. In addition, many researches have analysed the properties of hardened recycled aggregate concrete, but few of them have focused on the mixing method and the consequences that it has on the properties of concrete. In this research, recycled aggregate concrete using dry, with extra water supply, and saturated recycled aggregate has been prepared. The different mixing conditions induce differences the micro and macroporosity of concrete that have been evaluated by computerized axial tomography, scanning electron microscopy and a new developed methodology, based on digital image analysis, developed to analyse the distribution and size of macroporosity. The software has been implemented in Matlab $\odot$ and is available to the readers of the journal for downloading and use. The results show that the dry and saturated recycled aggregate lead to very different concrete properties. On the one hand, the use of dry aggregate causes a local reduction of the $\mathrm{w} / \mathrm{c}$ ratio, increasing heterogeneity and decreasing workability. On the other hand, the saturated aggregate incorporates extra water by adsorption that causes an increase in the water/cement ratio, thus increasing the porosity volume and size of the new mortar of the recycled aggregate concrete.
\end{abstract}

Keywords: recycled aggregate concrete; porosity; macroporosity; XCT; SEM; IMA 


\section{Introduction}

Recycled aggregate concrete (RAC) is a sustainable composite material with hardened properties depending on the characteristics of the components and the interactions between them. One of its two main components is recycled aggregate (RA). It has been studied in depth how the coarse recycled aggregate fraction (CRA) (Guo et al., 2018, Sagoe-Crentsil et al., 2001) and fine recycled aggregate fraction of RA (FRA) (F. Rodrigues et al., 2013, L. Evangelista and J. de Brito, 2007) influence RAC, most of it sourced from concrete but also from ceramic structural (Medina et al., 2016) and non-structural precast components (Juan-Valdés et al., 2018). The most suitable RA is the one coming from demolished concrete structures or precast components, where the main difference from natural aggregate (NA) is the attached mortar (M.S. de Juan and P.A. Gutiérrez, 2009). In general, aggregates are mixed using traditional techniques and methodologies, although CRA tend to be less round, lighter and less resistant than NA. In this sense, the most often used methodologies to calculate the concrete aggregate structure are the Fuller method (Thomas et al., 2014, Sabai et al., 2013, Thomas et al., 2016), Bolomey method (Jiménez et al., 2014, Kong, 2003, Zhang et al., 2012), de la Peña method (Medina et al., 2016), ACI method (Choi and Yun, 2012, Fathifazl et al., 2011, Yang et al., 2008) and Faury method (Thomas et al., 2018, Valdés and Rapimán, 2007). In addition, specific methodology to use CRA has even been proposed to obtain concrete with the same cement paste/natural aggregate ratio as traditional concrete: the "equivalent mortar volume method" (Fathifazl et al., 2009).

The other major component of concrete is the mortar matrix in which the CRA is embedded. This matrix is formed by four different phases: cement paste, sand, interfacial transition zone between cement paste and sand (ITZ1) and pores. The latter are formed by spaces or cavities occupied by air and/or water with regular or irregular geometries that form a complex 3D network. Concrete durability depends on the resistance offered to the penetration of aggressive external agents into the porosity network. Water absorption is the main factor in the deterioration of concrete not subjected to mechanical actions and water transport depends on the type, size, distribution and interconnection of the pores. These parameters and the dissolved aggressive agents can cause premature deterioration of steel reinforcement and of concrete itself. Li et al. have analysed the mechanical properties and durability of RAC by the ITZ analysis with different types of RA, modelling the failure systems caused by the propagation of fissures and the effect of nanoparticles (Lei et al., 2018, Li et al., 2012, Li et al., 2017, Li et al., 2018).

The concrete porosity network can be classified according to the pore size. Gel porosity is formed by spaces between layers of hydrated calcium silicates (C-S-H) with layers' separation of $18 \AA$, resulting approximately in $28 \%$ of the porosity present in solid C-S-H (Metha, 1986). This pore size is too small to have adverse effects on strength or permeability. The capillary porosity is volume not filled by the hydration products and depends on the degree of hydration and the water/cement $(\mathrm{w} / \mathrm{c})$ ratio of concrete. The hydration products fill this space, decreasing the capillary porosity while gel porosity increases. In general, capillary porosity is interconnected by gel porosity. Koenders et al. (Koenders et al., 2014) have reported a correlation between the degree of hydration of the RAC and its mechanical properties, for the different water/cement ratio, with the distinction between dry and saturated aggregates. There is another porosity due to retained air during the mixing process of concrete. This air produces a porosity that depends on the mixing and compaction methods. Air porosity has a considerable size in relation to those previously mentioned. Capillary porosity presents an irregular shape and air porosity is spherical and affects strength and permeability (Metha, 1986).

Following traditional mixing methods, the higher porosity and absorption coefficient of CRA affect fresh mortar, reducing the $\mathrm{w} / \mathrm{c}$ ratio around the aggregate. This effect isolates the porosity of the 
CRA with a less permeable mortar around the aggregate (Thomas et al., 2013). To compensate this effect, more recently, it has been proposed to add an amount of extra water that would compensate the loss that takes place by aggregate absorption (Fiol et al., 2018). However, standards such as the Spanish one (Martín-Morales et al., 2011, Ministerio de Fomento - Gobierno de España, 2008) recommend the pre-saturation of CRA to avoid this effect but Silva et al. (Silva et al., 2016) showed that the incorporation of pre-saturated aggregate induce higher mechanical properties losses. Although it is known that pre-saturation of the CRA allows obtaining an equivalent w/c ratio for all the incorporation ratios. A comprehensive predictive formulation for RAC strength based on the "effective" w/c ratio and the initial moisture conditions of aggregates, has been proposed by Pepe et al. (Pepe et al., 2016) but there is not enough knowledge about how it affects the porosity of the mortar.

There are numerous methods to analyse the porosity of concrete and mortar. One of the most used in recent decades to analyse the distribution of micropores is mercury porosimetry but it is seldom used today for environmental issues and because other more sophisticated equipment, such as microtomography, have appeared. Traditionally open porosity has been obtained by water saturation, although saturation is a slow process and is influenced by the size and shape of the specimens. Modern methods such as microtomography (Thomas et al., 2018) allow access to the open and close porous network without affecting the material but only in very small samples. In addition, image analysis by backscattered electron images of polished sections were used to characterize the concrete (Hu, 2004, Lange et al., 1994).

In this study, two different CRA laboratory conditions were used, in order to analyse the influence of the mixing process: dry and saturated. Pepe et el. showed that the RA moisture clearly affect the performance of concrete (Pepe et al., 2014). In addition to performing an analysis of macro and micro porosity using computerized axial tomography (XCT) and scanning electron microscopy (SEM), a new methodology was developed, based on digital image analysis, to evaluate the distribution and size of the macroporosity. The software to perform this analysis has been programmed in Matlab@ and is available to readers of the journal for downloading and use (\$2.5).

\section{Methodology}

Fine limestone aggregate (FLA), two sizes of coarse limestone aggregate (CLA) and coarse recycled aggregate (CRA) were used. CRA is composed of $95 \%$ wt. $25 \mathrm{MPa}$ clean structural concrete. Fig. 1 shows the size grading of the aggregates.

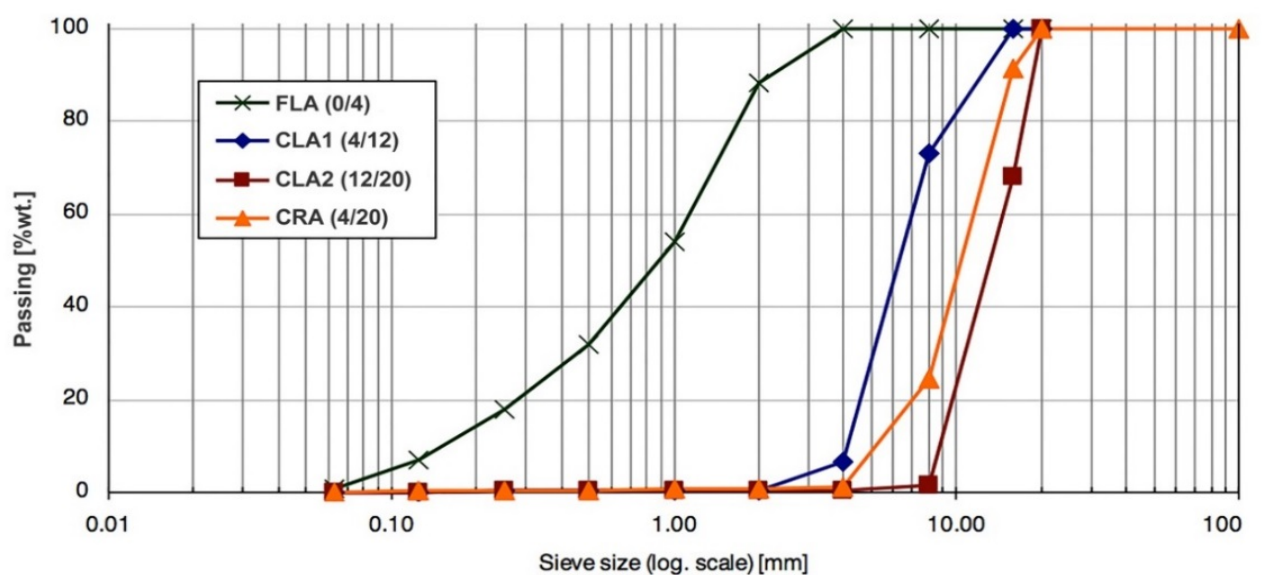

Fig. 1. Size grading of the aggregates.

Table 1 shows the main properties of the aggregates. $R$ is the relative density, SSS the saturated dry surface density, $A$ is the water absorption by weight, $P$ the open porosity by 
volume, $C$ the bulk density and $L A$ the Los Angeles index.

Table 1. Properties of the aggregates.

\begin{tabular}{lllllll}
\hline Aggregate & $\mathbf{R}\left[\mathbf{g} / \mathbf{c m}^{3}\right]$ & $\mathbf{S S S}\left[\mathbf{g} / \mathbf{c m}^{3}\right]$ & $\mathbf{A}[\%$ wt.] & $\mathbf{P}[\%$ vol.] & $\mathbf{C}\left[\mathbf{g} / \mathbf{c m}^{3}\right]$ & LA [\%] \\
\hline CLA1 (4/12) & 2.51 & 2.55 & 1.8 & 4.7 & 1.53 & 31 \\
CLA2 (12/20) & 2.54 & 2.59 & 1.6 & 4.0 & 1.53 & - \\
CRA (4/20) & 2.32 & 2.31 & 5.3 & 12.3 & 1.42 & 42 \\
\hline
\end{tabular}

Portland CEM I 52.5 R cement has been used as binder. Table 2 shows its chemical composition.

Table 2. Chemical composition of cement.

\begin{tabular}{llllllllll}
\hline Component: & $\mathrm{CaO}$ & $\mathrm{SiO}_{2}$ & $\mathrm{SO}_{3}$ & $\mathrm{Al}_{2} \mathrm{O}_{3}$ & $\mathrm{Fe}_{2} \mathrm{O}_{3}$ & $\mathrm{MgO}$ & $\mathrm{K}_{2} \mathrm{O}$ & $\mathrm{C}$ & $\mathrm{TiO}_{2}$ \\
\hline \% in wt.: & 69.60 & 18.60 & 3.22 & 3.10 & 2.66 & 1.17 & 0.54 & 0.47 & 0.17 \\
\hline
\end{tabular}

Two laboratory conditions were used in order to analyse the influence of the mixing process: dry and saturated aggregates. Control/limestone (Lilac) and recycled aggregate (RiAC) concrete mixes were prepared, where $i=\mathrm{S}$ indicates saturated and $i=\mathrm{D}$ dry condition before mixing. In addition, three substitution ratios of CLA with CRA were tested: $20 \%$ vol.; $50 \%$ vol. and $100 \%$ vol. To saturate the aggregate, after dry weighting, it was immersed in water, inside a perforated container, for $10 \mathrm{~min}$ and, then, drained for another $10 \mathrm{~min}$.

Table 3. Concrete mix proportions (by $\left.\mathrm{m}^{3}\right)$.

\begin{tabular}{lllll}
\hline Concrete: & LiAC & RiAC20 & RiAC50 & RiAC100 \\
\hline FLA $(0 / 4 \mathrm{~mm})(\mathrm{kg}):$ & 714 & 744 & 710 & 715 \\
CLA1 $(4 / 12 \mathrm{~mm})(\mathrm{kg}):$ & 882 & 665 & 414 & 0 \\
CLA2 $(12 / 20 \mathrm{~mm})(\mathrm{kg}):$ & 122 & 92 & 57 & 0 \\
CRA $(4 / 20 \mathrm{~mm})(\mathrm{kg}):$ & 0 & 189 & 471 & 874 \\
\hline Cement $(\mathrm{kg}):$ & 380 & 380 & 380 & 380 \\
Water $(\mathrm{kg})$ for $i=\mathrm{D}:$ & 205 & 209 & 212 & 220 \\
Water $(\mathrm{kg})$ for $i=\mathrm{S}:$ & 178 & 178 & 179 & 182 \\
\hline
\end{tabular}

A $17 \pm 3 \mathrm{~cm}$ slump of fresh concrete for a $0.5 \mathrm{w} / \mathrm{c}$ ratio is obtained. A higher amount of water is required for dry aggregate. In both cases, dry and saturated, an increase in the amount of water with the ratio of substitution of CLA with CRA is required in order to maintain the effective w/c ratio. An ideal mixing method should maintain the porosity and absorption of the new mortar for all recycled aggregate incorporation ratios and the increase of recycled aggregate concrete absorption should be exclusively due to the increase of water absorption of the recycled aggregate. However, it is not possible to access isolated recycled aggregates by saturation methods. Therefore, the values of porosity and absorption measured by saturation methods are not proportional to the incorporation ratio.

\subsection{Physical and mechanical properties}

Density and porosity were obtained following EN-12390-7 (EN-12390-7, 2009). The absorption 
coefficient is the result of comparing the absorbed water and specimen weights. Compressive strength was determined according to EN 12390-3 (EN 12390-3, 2009) and EN 12390-4 (EN 12390-4, 2001). The physical properties were obtained using sub-specimens $(15 \varnothing \times 10 \mathrm{~cm})$ obtained from cutting standard $15 \varnothing \times 30 \mathrm{~cm}$ cylindrical specimens at 28 days. Compressive strength was determined using 7 standard $15 \varnothing \times 30 \mathrm{~cm}$ cylindrical specimens at 28 days.

\subsection{Porosity by computerized tomography (XCT)}

A XCT equipped with X-ray source of $100 \mathrm{kV}$ and $100 \mu \mathrm{A}$ was used to analyse 30x15x15 mm concrete specimens obtained by cutting the centre of standard specimens. The analysed volume of interest (VOI) of each sample is approximately $120 \mathrm{~mm}^{3}$. The equipment identifies the total porosity with a voxel size resolution of $30 \mu^{3}$.

\subsection{Scan electron microscopy}

A scan electron microscope (SEM) equipped with an X-ray detector was used to analyse the cement paste of concrete. Sample surfaces of $10 \times 10 \mathrm{~mm}$ were obtained by cutting, coated with gold and observed in order to compare the cement paste microstructure.

\subsection{Image macroporosity analysis (IMA)}

A specific methodology and software have been developed to quantify the accessible and nonaccessible macroporosity (> $100 \mathrm{am}$ ) using digital image analysis. A Matlab $\odot$ based program (IMA) has been developed for this purpose (see $\S_{i}$ Error! No se encuentra el origen de la referencia. to download it). IMA is based on the recognition of porosity from a picture of the surface of the sample by contrasting colours. The picture for analysis must be taken after the preparation of the surface of the samples. In this case, specimens with $150 \mathrm{~mm}$ diameter and $300 \mathrm{~mm}$ height were used in order to obtain results from a circular surface at different levels of the height of the specimen. To prepare the samples, the first step is to cut the standard specimen trough a perpendicular plane to the axis of the cylinder. If the cut is made with a suitable saw, polishing the surface will not be necessary. In this case, it was decided to make four cuts on the cylindrical sample: one in the upper part and another one in the lower part of the specimen, to remove approximately $1 \mathrm{~cm}$ of the concrete surface exposing the aggregate and internal porosity; the other two cuts were made to divide the specimen into three sub-specimens (Fig. 2). This results in six surfaces inside the sample that can be analysed by IMA. Once the cross-sections of the test specimens have been obtained, it is necessary to prepare the surface. This is a very important part of the preparation method to obtain accurate results from the analysis.

Fig. 2 shows the sequence to prepare the surfaces. For IMA to locate pores on the surface, it is necessary a good contrast between the flat surface or background and the pore. It was decided to use two high-contrast colours: white for the pore and black for the background.

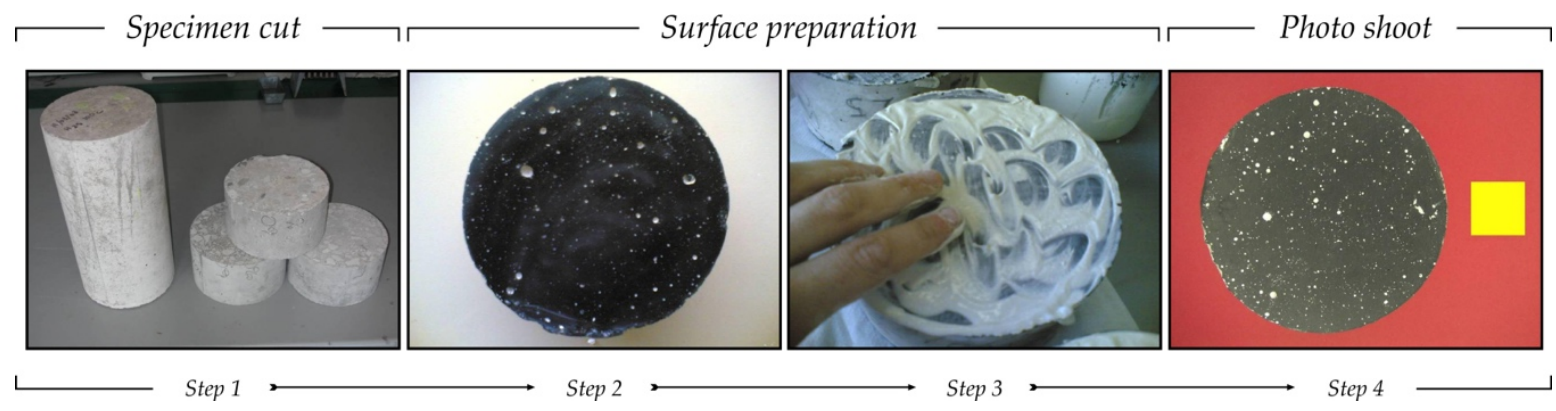

Fig. 2. Sequence of specimen preparation for IMA. 
The second step after cutting, cleaning and drying the surface is to paint it (Fig. 2, step 2) with a thin layer of lustreless black acrylic paint. It is important that the paint is fluid to avoid filling the pores and dull to avoid reflections, and to use a diffuser-atomizer.

Fig. 2 (step 3) shows how the surface is impregnated with a fluid paste of water and white rapid hardening cement, with specific Blaine surface area of $405 \mathrm{~m}^{2} / \mathrm{kg}$. The fineness of cement guarantees filling the pores and cavities of the sample. To ensure that cement penetrates all macropores, circular movements pressing with fingers should be performed until the mix becomes consistent. After a few minutes, the excess cement can be removed keeping the white paste inside the pores and after 1 hour the surface can be cleaned using a wet cloth, highlighting the black background colour. Fig. 2 (step 4) shows the picture to be analysed by IMA. The photo is taken with a background colour different from white or black. Fig. 2 (step 4) shows the red background used. In this process, the illumination of the test specimen should be as uniform as possible, avoiding shadows or bright spots. The minimum pore size is limited by the resolution of the image; the smallest pore that can be detected with IMA is that with 1-pixel digital size. With this method the quantifiable minimum size is around $100 \mu \mathrm{m}$ pore diameter. However, IMA allows using other minimum pore sizes. Fig. 2 (step 4) shows a square of dimensions $(40 \times 40 \mathrm{~mm})$ photographed with the test specimen for the size calibration of IMA. This calibration method allows analysing samples with different sizes from the usual $150 \mathrm{~mm}$ diameter.

The software allows obtaining the macropore density, dividing the number of pores detected on the cut surface by the corresponding area, and the macroporosity, dividing the total area of pores by the total analysed area. The distribution of macroporosity at different heights of the specimen can also be obtained. The software automatically compares and makes figures of the pore size distribution vs. the distance from the centre of the specimen, the number of pores vs. the distance from the centre of the analysed area and the number of pores compared with the pore size. Finally, the IMA software creates a text file with a list of all the detected macropores and its position using $x$, $y, z$ coordinates that allows the user to make further analysis.

\section{Results and discussions}

\subsection{Physical and mechanical properties}

Fig. 3 left shows the relative density of LSAC (with saturated aggregate), LDAC (with dry aggregate) and $20 \%, 50 \%$ and $100 \%$ RSAC (with saturated aggregate) and RDAC (with dry aggregate) concrete mixes. Fig. 3 right shows the absorption coefficient of the same mixes.
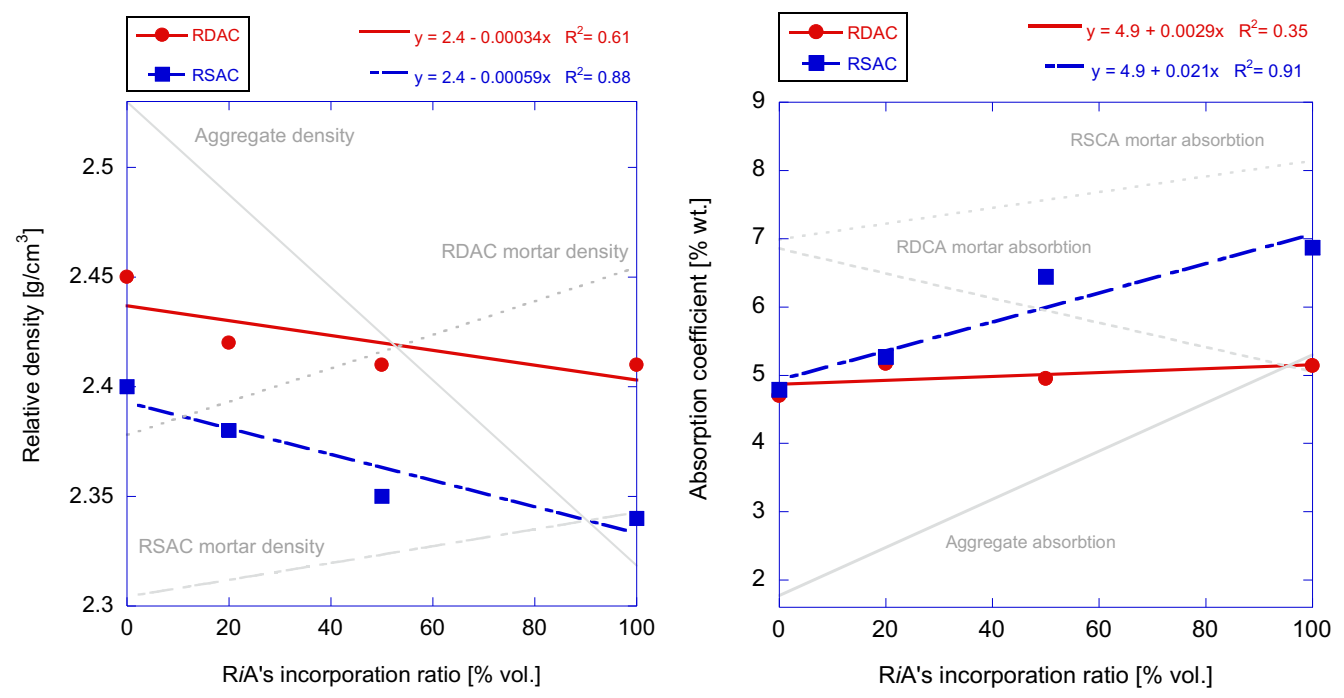

Fig. 3. Relative density (left) and absorption coefficient (right) vs. RiA's incorporation ratio.

The density of RSAC and RDAC shows slight differences. Both the RDSAC's and RDAC's density decrease with the incorporation of recycled saturated aggregate (RSA) and recycled dry 
aggregate (RDA), because on the one hand of the lower density of recycled aggregate and, on the other, of the mortar differences induced by the aggregate production and mixing method. The influence of RSA is higher than that of RDA. In Fig. 3 left, the average density of the aggregate skeleton and the density of the mortar are represented, calculated thought concrete mix proportions, using concrete density, ratio of each coarse aggregate and aggregates' density. In the case of RDAC, the density is similar to that of the aggregate skeleton at $50 \%$ substitution. For substitutions higher than $50 \%$, the density of the mortar increases considerably. However, below 50\% substitution, a mortar with high porosity is expected. In the case of RSAC, the optimal combination, where both components (new mortar and aggregate) show the same density, is found at $90 \%$ substitution.

In the case of the absorption coefficient (Fig. 3 right), RDAC shows no variation and RSAC increases its absorption with the substitution ratio. The RDAC mortar absorption should decrease in order to compensate the increased absorption of the aggregate. In fact, this effect should be attributed to the RDA itself, which causes a reduction of the w/c ratio around it, as reported by Thomas et al. (Thomas et al., 2016). However, when RSA is incorporated, the absorption coefficient of RSAC increases with a slightly lower slope than that of the RSA itself. This effect indicates that the absorption of the mortar increased. The trend lines of the absorption of the RDA and RDAC mortar converge when the recycled aggregate incorporation ratio is slightly over $90 \%$ vol. On the contrary, the RSA and RSAC mortar trend lines do not converge because of RSA not absorbing water, since its pores are already pre-saturated.

Fig. 4 left shows the open porosity of RDAC and RSAC for different incorporation ratios. The open porosity, determined by saturation, of RDAC and RSAC increases with the incorporation ratio. The slope of the linear adjustment of RSAC's open porosity is significantly higher than that of RDAC. These results are consistent with the absorption coefficient results. However, in the ideal case of the porosity of the mortars of all concrete mixes being the same, the increase of absorption should be exclusively due to the increase of absorption of RDA or RSA. However, in the case of RDAC mortar, the lower porosity of the mortar blocks access to the porosity of RDA. Thus, in this case, the mixing methodology (dry aggregate) causes a change of the results of the porosity if they are obtained by saturation. For this reason, it is expected that other methodologies of direct measurement, such as tomography or surface analysed by IMA, will provide more consistent results.
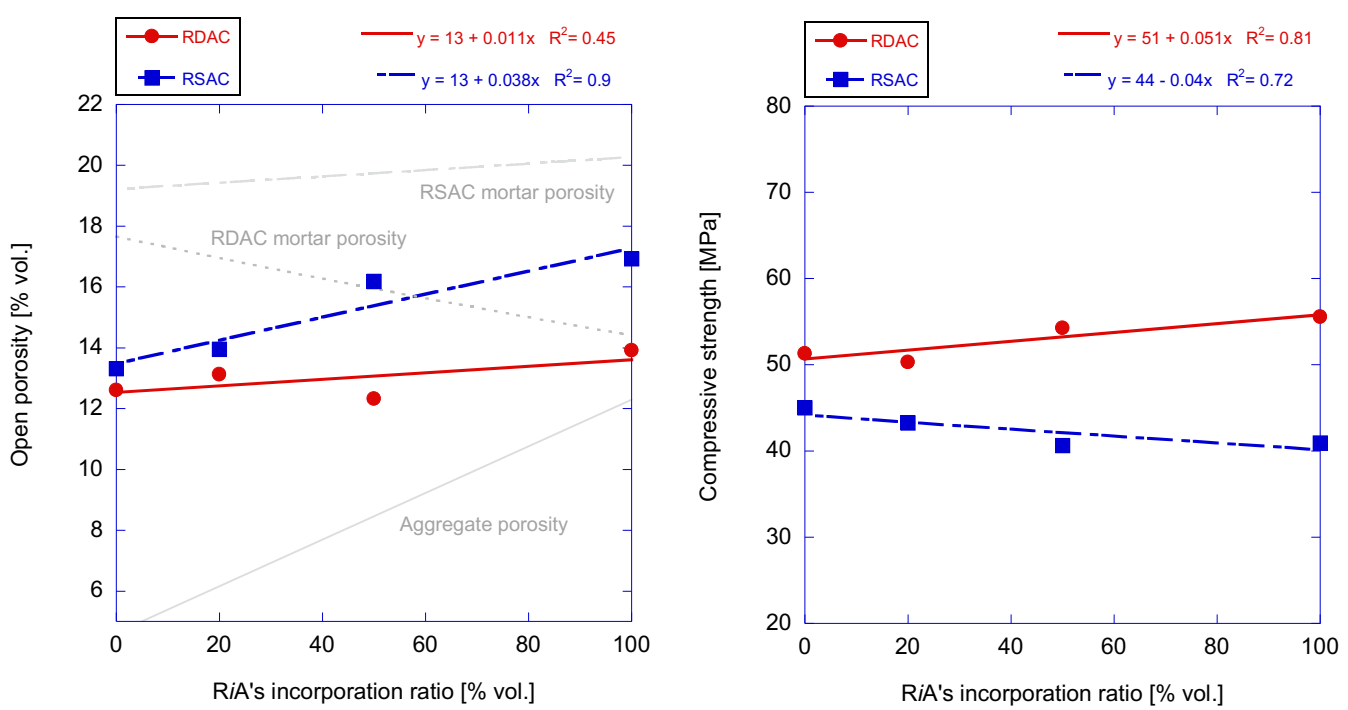

Fig. 4. Open porosity (left) and compressive strength (right) vs. RiA's incorporation ratio.

Fig. 4 right shows the results of compressive strength of the studied concrete mixes versus incorporation ratio. It clearly shows that the mixing methodology caused significant differences. RDAC shows a slight increase in compressive strength with the incorporation ratio while RSAD shows a slight decrease. The increase in compressive strength must be a consequence of a decrease in the effective w/c ratio because of the water absorption of RDA. This means that the extra water 
does not compensate the RDA's absorption. The aggregate absorption in this case has been underestimated because the $\mathrm{w} / \mathrm{c}^{\prime} \mathrm{s}$ decrease compensated even the compressive strength diminution expected from the incorporation of RDA. In the case of RSAC, a decrease in compressive strength with incorporation of RSA is observed. For $100 \%$ incorporation it is approximately $10 \%$, a value reported by other authors (Thomas et al., 2016) as expected loss of this property after complete substitution of natural with recycled concrete aggregate of this type.

\subsection{Porosity by computerized tomography (XCT)}

$\mathrm{XCT}$ provides quantitative information about the distribution of the porosity of the analysed samples. In order to analyse the effect of RSA on RSAC, Fig. 5 shows an example sequence of four types of RSAC. The mix with lowest number of pores and smallest volume of porosity is LiAC. As RiA is incorporated into RiAC, the number and volume of pores increases. In both cases, an increase in porosity can be seen due to the incorporation of the RSAC itself and the porosity of the new mortar.
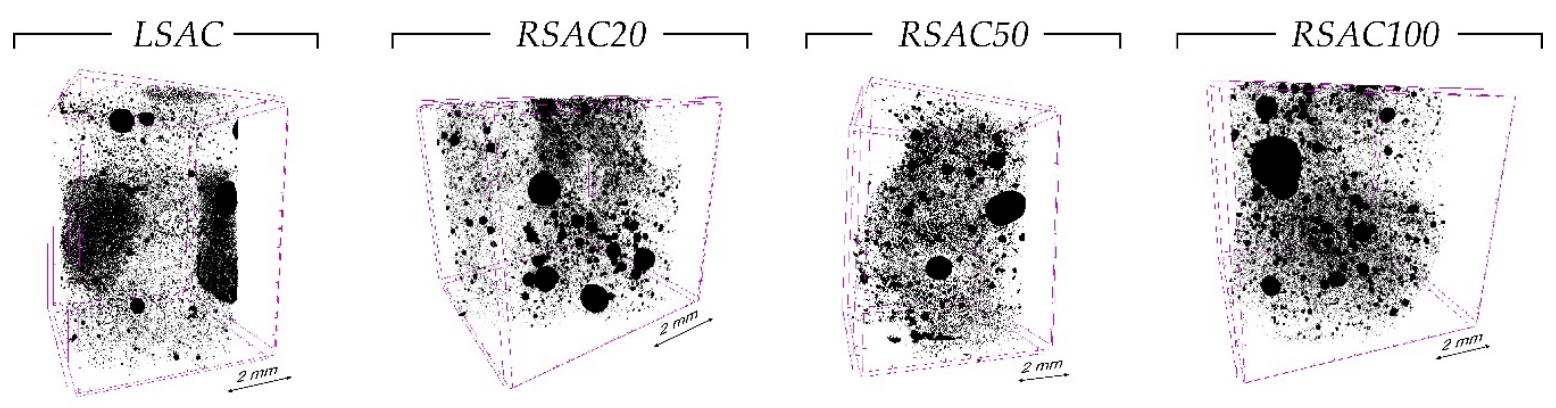

Fig. 5. Sequence of the qualitative analysis of the specimen of LSAC, RSAC20, RSAC50 and RSAC100.

Fig. 6 shows the total porosity and largest pore volume of the analysed concrete mixes. The first interesting aspect is that LiAC's total porosity analysed by tomography is notably less than that obtained by the water saturation method, $1.5 \%$ vol. and $13 \%$ vol. respectively. This is due to the resolution of the equipment. Water is able to saturate a larger volume of porosity because it penetrates smaller pores and capillaries. In fact, for the tomography device, the natural aggregate does not present any porosity. Therefore, the evaluated total porosity corresponds to pores bigger than $30 \mu \mathrm{m}^{3}$. Total porosity increases with the incorporation ratio, due to the adhered mortar of RiAC, in a different way for RDAC and RSAC. As with the accessible porosity determined by saturation, RSAC's porosity increases more than that of RDAC because of the different porosity of the new mortar. Samples with small imperfections, such as cracks or fractures, can be evaluated by this technique as porosity. (Moretti et al., 2018) used XCT results to observe large voids, cracks, and inhomogeneities, and associate them with the mechanical behaviour of the material and compare the porosity of mortars with additions. 

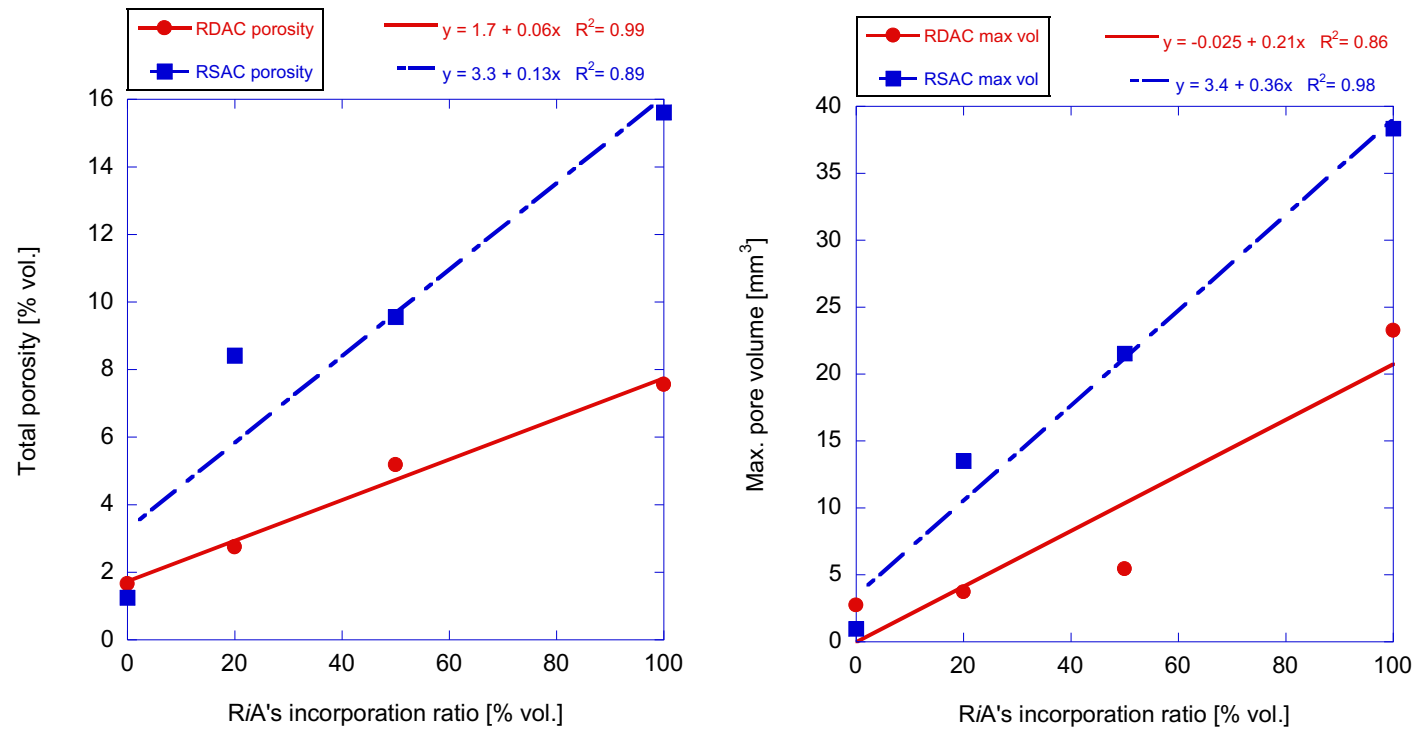

Fig. 6. Total porosity (left) and largest pore size (right) vs. RiA's incorporation ratio.

RSAC100 presents a total porosity 50\% higher than RDAC100, caused by a larger pore total volume. Fig. 6 right shows the maximum pore size, confirming that in RSAC not only the pores volume is larger but also their size. This effect can be a consequence of two different modes of action of the superplasticizer. On the one hand, the excess of adsorbed water, located on the surface and between particles of RSA, causes an increase of the w/c ratio and consequently a higher porosity. In addition, the superplasticizer of RSAC is dissolved in a larger volume of water than in RDAC, reducing the effectiveness and resulting in greater pores due to retained air. In this case, as usual, the superplasticizer was added at the last stage of mixing, when the aggregate is largely pre-saturated. However, if the admixture is added to the mix at the initial stage or mixed with the mixing water, part of the water of RDAC, containing dissolved admixture, is absorbed by the aggregate and the effect should decrease.

\subsection{Scan electron microscopy}

Fig. 7 shows a detail of the RSAC0 mortar on the left and of RSCA100 on the right. In the micrographs, macropores of $100 \mu \mathrm{m}$ diameter can be observed, due to air retained during the mixing process. In the case of concrete with LSAC, the paste is more compact and closed than in the case of concrete manufactured with $100 \%$ RSAC.
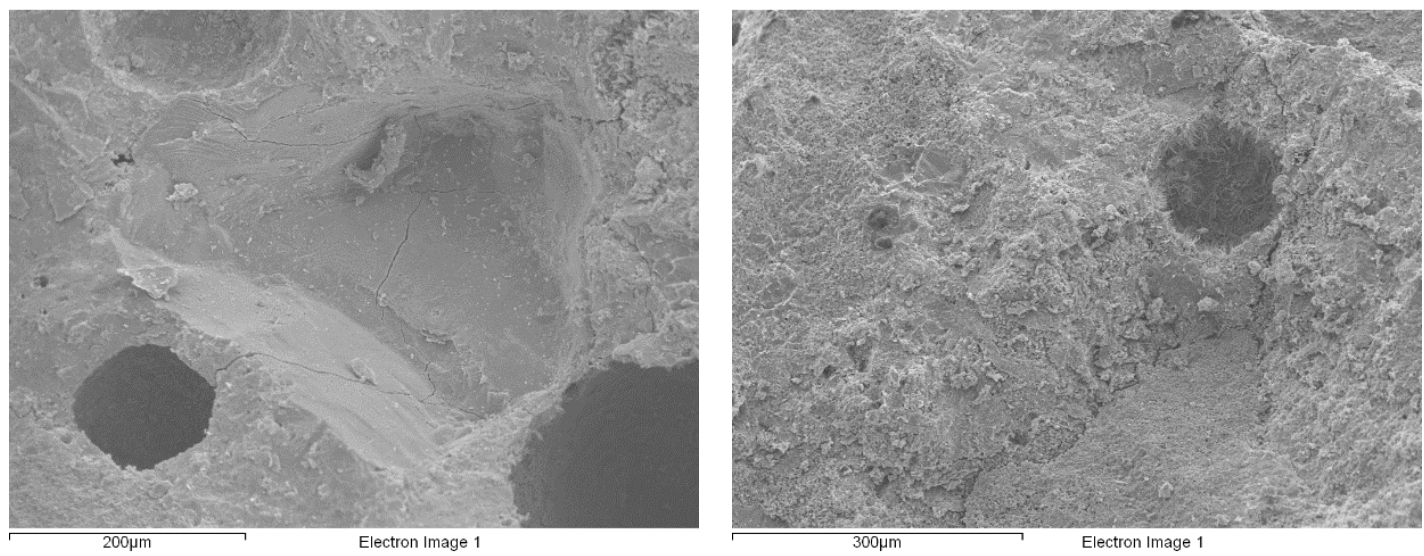

Fig. 7. Micrograph of a RSACO (left) and RSCA100 (right). 
From the observations made with SEM, it can be deduced that the cement paste of mixes with RSA incorporation is more open than that of those with RDA, because of the higher water content. The excess water generates a gel porosity formed by spaces between layers of C-S-H. This porosity represents more than $1 / 4$ of the total porosity, so it has a special relevance on the total porosity of concrete.

Juan-Valdés et al. (Juan-Valdés et al., 2018) used the chemical composition of ceramic recycled aggregate to identify the natural and recycled aggregates and Angelin et al. (Angelin et al., 2017) used manual and automatic counting of micro-voids from high magnification micrographs showing that the higher the percentage of substitution of sand by rubber, the greater the amount of voids in the cement matrix. The ettringite inside the pore of RSA100 (Fig. 7) suggests that this porosity is due to a mortar pore attached to the CRA. No ettringite is found in the pores of the RSAC0 sample. In the case of recycled aggregate concrete mixes in which similar cements and w/c ratios are used, it is difficult to identify the new mortar from the adhered mortar to the original aggregate.

\subsection{Image macroporosity analysis (IMA)}

Table 4 shows the macropore density and the macroporosity of the concrete at different heights, $\mathrm{S} 1=30 \mathrm{~cm}$ (top), $\mathrm{S} 2=20 \mathrm{~cm}, \mathrm{~S} 3=10 \mathrm{~cm}$ and $\mathrm{S} 4=0 \mathrm{~cm}$ (bottom) of the specimen. There is a gradient in the distribution of macropores ascending in height. All the analysed test specimens show an increase of the number of pores and macroporosity in height. However, the observed increase is different depending on which property is analysed, macropore density or macroporosity, and different for the different degrees of substitution and mixing method. Regarding the macropore density in height of RSAC, a remarkable evolution is observed. In S4, the lowest value, the number of found pores is between 245 and 302, for RSAC0 and RSAC100, with a singularity in RSAC20. In general terms, the number of macropores increases with the substitution ratio. Macropore density increases in height for all substitution ratios gradually until upper section S1, with twice the density of section S4. A similar evolution is observed in RDAC. However, this mix shows a considerably more closed structure. In this case, the evolution in height of the macropore density is attenuated, being especially low in the case of RDACO.

The macropore density increase in height should be due to the nature of the macropores. The spherical shape observed in the cut surface of Fig. 2, internal structure of Fig. 5 and microstructure of Fig. 7 suggests that most macropores are the result of occluded air bubbles. In this sense, the higher fluidity of fresh RSAC favours occluded air gradient in height, influencing the macroporosity, expressed as a percentage of pore surface compared to the total analysed area, more than the pores' density. Especially for RDAC, the incorporation of recycled aggregate entails a remarkable increase of the macroporosity, for all heights.

Table 4. Macroporosity of RSAC and RDAC.

\begin{tabular}{|c|c|c|c|c|c|c|c|c|c|}
\hline \multirow{2}{*}{$\frac{\text { Concrete: }}{\text { RiAC [\%vol.]: }}$} & & \multicolumn{4}{|c|}{ RSAC } & \multicolumn{4}{|c|}{ RDAC } \\
\hline & & 0 & 20 & 50 & 100 & 0 & 20 & 50 & 100 \\
\hline \multirow{4}{*}{$\begin{array}{l}\text { Macropore density } \\
{\left[\text { pores } / \mathrm{cm}^{2}\right] \text { : }}\end{array}$} & S1 & 2.94 & 2.82 & 4.50 & 3.64 & 0.55 & 0.56 & 1.90 & 1.97 \\
\hline & S2 & 1.64 & 2.50 & 2.42 & 2.20 & 0.20 & 1.92 & 3.58 & 2.32 \\
\hline & S3 & 1.77 & 2.43 & 3.19 & 2.61 & 0.29 & 1.34 & 2.46 & 2.44 \\
\hline & $\mathrm{S} 4$ & 1.39 & 2.33 & 2.06 & 1.71 & 0.48 & 1.34 & 2.39 & 2.00 \\
\hline \multirow{4}{*}{$\begin{array}{l}\text { Macroporosity } \\
\text { [\%surface]: }\end{array}$} & $\mathrm{S} 1$ & 1.81 & 2.32 & 3.02 & 2.94 & 0.44 & 1.51 & 2.38 & 2.47 \\
\hline & $\mathrm{S} 2$ & 1.08 & 2.34 & 2.18 & 2.60 & 0.49 & 1.39 & 2.24 & 2.04 \\
\hline & S3 & 1.00 & 1.75 & 1.89 & 2.79 & 0.40 & 1.21 & 2.16 & 1.87 \\
\hline & $\mathrm{S} 4$ & 1.37 & 1.81 & 1.83 & 2.61 & 0.39 & 0.89 & 1.67 & 1.58 \\
\hline
\end{tabular}


Fig. 8, shows the number of pores vs. distance from the centre of RSAC100 (left) and RDCA100 (right) as example of the differences between these mixes. It can be observed that the highest pore density is found in the perimeter of the cylindrical specimen, with an increase in the number of macropores with the increase of the substitution ratio.
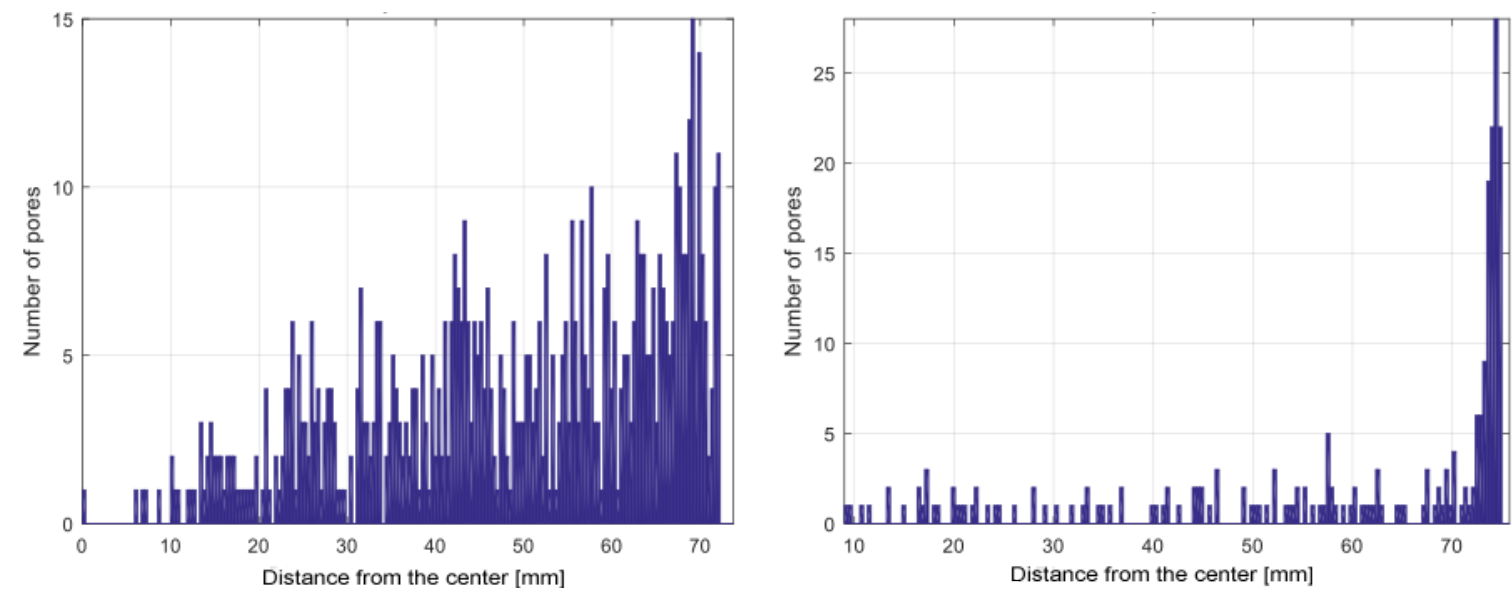

Fig. 8. Number of pores vs. distance from the centre of RSAC100 (left) and RDCA100 (right).

An increasing number of pores from the centre to perimeter of the specimen is observed in all specimens. Likewise, RDCA100 presents a higher perimeter macropore density and a lower inside density. The number of pores with respect to the radial distance of RSCA100 is homogeneously distributed but increases from the centre to the perimeter of the specimen. In addition, it is observed that the number of pores concentrated on the exterior of the specimen is not higher in RSCA100 than in RDCA100. However, the global number of macropores is higher in RSCA than in RDCA and, in general, RSCA presents a higher number of pores and distributed more homogeneously than RDCA. The lower w/c ratio of RDCA implies, as expected, a significant reduction in the total number of pores. RSCA20 shows a strong increase in the total number of pores and, especially, those found in the perimeter of the specimen relative to RSCA0. RDCA20 does not show a significant increase in the number of macropores or notable differences in its distribution. RDCA100 analysis shows that the number of pores increases considerably compared to the other RDCA.

There is an evident relationship between the number of pores and their size. The pores distribution with respect to the distance from the centre of the specimen shows some singularities. However, in general terms the incorporation ratio of RiA is directly related to number and density of macropores.

Fig. 9 shows the number of pores vs. pore size of RSAC100 (left) and RDCA100 (right). The distribution of the number of pores by size provides valuable information on the distribution of macroporosity. On the one hand, an exponential behaviour is observed in all studied specimens, with a much higher number of small pores. On the other, both the incorporation of recycled aggregate and the saturated aggregate condition cause recycled aggregate concrete to have larger pores. Fig. 9 shows that the average maximum size for RSAC100 and RDCA100 are $18 \mathrm{~mm}^{2}$ and $14 \mathrm{~mm}^{2}$ respectively. If all the $2 \mathrm{D}$ detected pores were spherical and cut by a plane that coincides with the largest diameter, the average radius of the macropores would be $2.4 \mathrm{~mm}$ and $2.1 \mathrm{~mm}$ respectively. These values would provide a maximum volume of macropores of $57 \mathrm{~mm}^{3}$ and $39 \mathrm{~mm}^{3}$ respectively. These values are higher than those found by XCT, $40 \mathrm{~mm}^{3}$ and $25 \mathrm{~mm}^{3}$ respectively. This discrepancy can be due to the assumption that all $2 \mathrm{D}$ detected pores correspond to sections in the middle of the sphere overrating 3D volumes by $40 \%$. Therefore, 2D obtained macropore sizes should be multiplied by a factor of 0.6 to extrapolate them to 3D.

Results show that the number of smaller than $2 \mathrm{~mm}^{2}$ size macropores is much higher than that of pores of other sizes. In addition, RSAC shows an increase with the incorporation CiRA ratio relative to that observed in RDAC. However, in the case of RSAC0 and RDAC0, the maximum size 
and number of pores are similar. The results show that the maximum macropore size increase, both in RSAC and RDAC, for 50\% and 100\% CiRA incorporation.
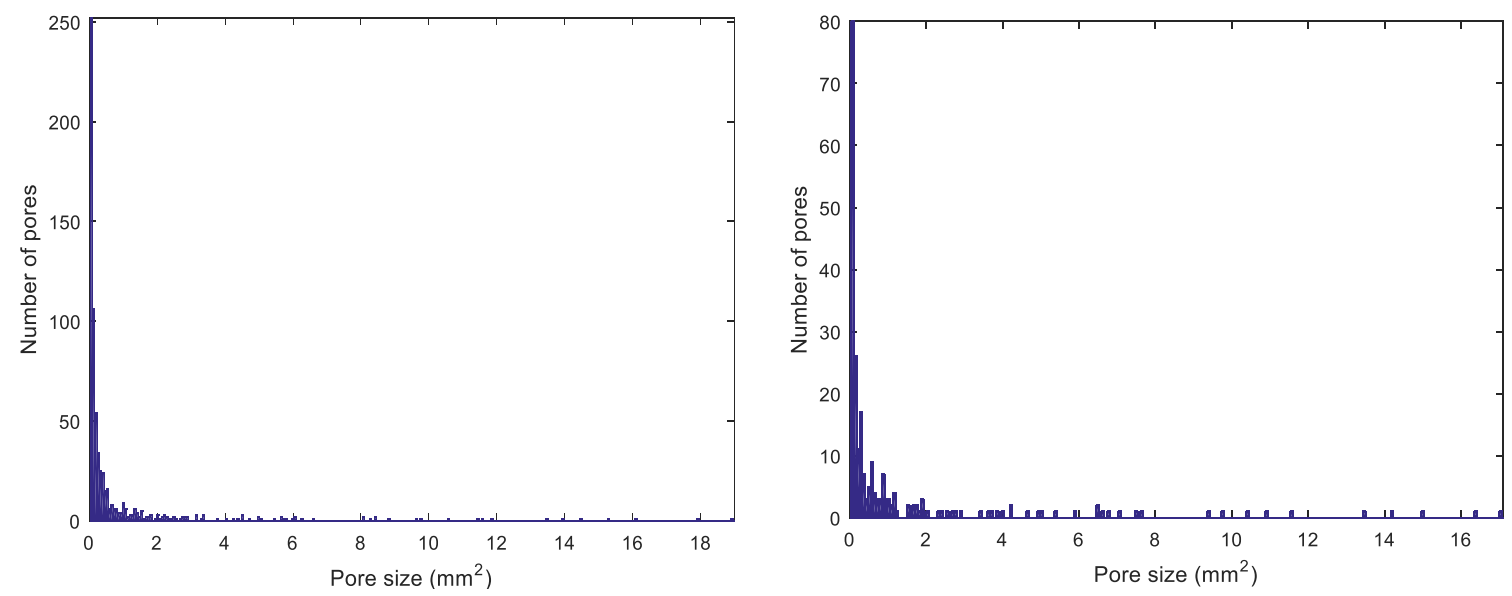

Fig. 9. Number of pores vs. pore size of RSAC100 (left) and RDCA100 (right).

Fig. 10 shows the pore size distribution vs. distance from the centre of RSAC100 (left) and RDCA100 (right). In the figure, one point corresponds to a macropore and the colour scale on the right of Fig. 10 solves the problem of detecting more than 1 macropore at the same radial distance. The colour corresponds to the number of macropores detected in one position. A clear tendency of larger pores in the perimeter in all the analysed specimens is observed, accentuated when the RiA's incorporation ratio increases. Similarly, the pore size of RSAC100 and RDCA100 is higher than that of RSAC0 and RDCA0. It is also observed that the number of macropores decreases as larger sizes are considered. Fig. 10 shows again that the size of the macropores of RSAC100 is larger than that of RDCA100. However, this representation reveals a clear tendency of larger macropores to be located away from the axis of the specimen. In addition, the observation of RSAC100's macropore distribution reveals a higher concentration of pores of smaller size than that of RDAC100. All RSAC and RDAC show a macropore size's increase as the distance from the centre of the analysed section increases and an increase in the number of macropores with respect to RiA's incorporation ratios.
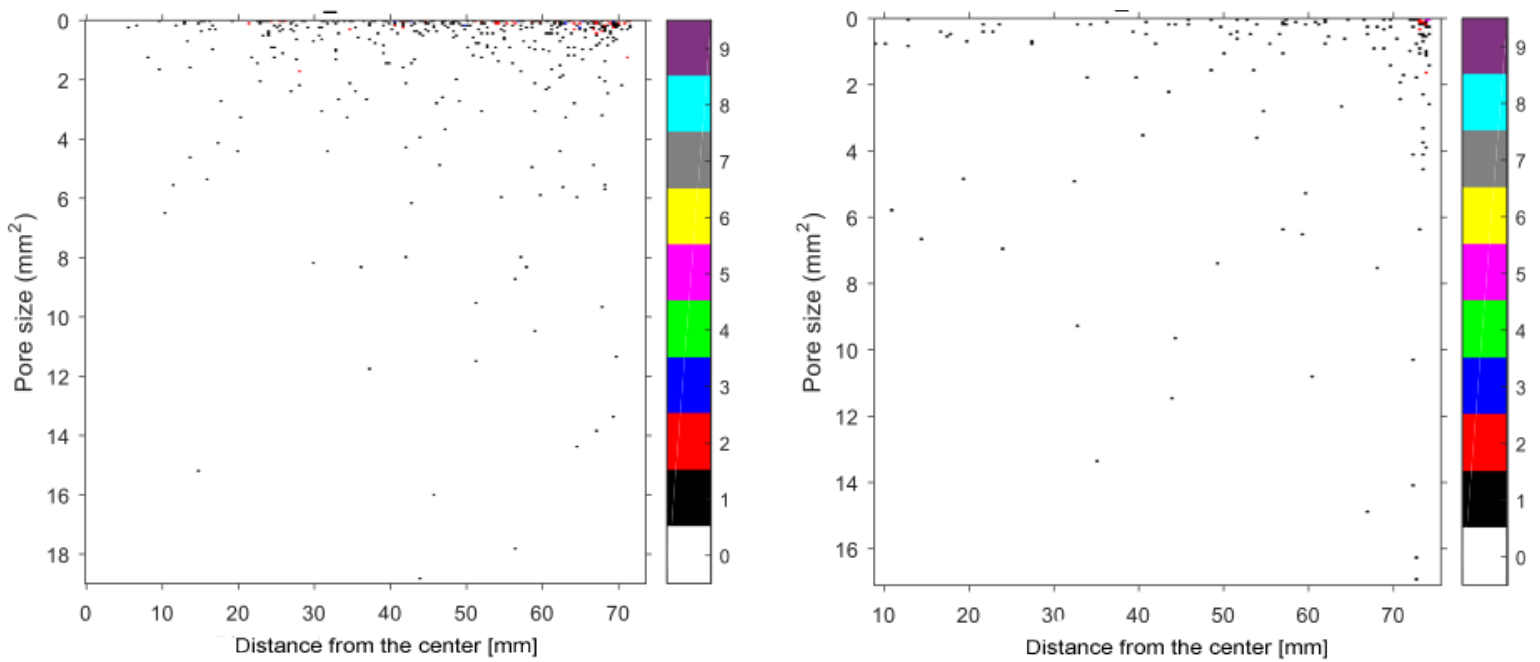

Fig. 10. Pore size distribution vs. distance from the centre of RSAC100 (left) and RDCA100 (right).

Fig. 10 shows that the distribution is limited by a diagonal line between the upper left vertex or point $(0,0)$ and the lower right vertex or point $(75, \max$ Size $)$ over which most of macropores are found. In general terms, the slope of the line that limits the location of the macropores in these diagrams presents a higher value as the incorporation ratio increases and, on the other hand, higher in RSAC than in RDAC. RSAC shows a clear reduction in the number and size of macropores with respect to 
RDAC with the same substitution ratio. Regarding the results corresponding to RDAC, both the size and number of macropores present the same trend as before: an increase with the incorporation ratio. However, the differences in number and density of macropores between RSAC0 and RDAC0 are lower than in others RiA incorporation ratios. There is a direct relationship between i) macroporosity, open porosity and non-accessible porosity, and ii) density of concrete.

This software has been used successfully in the analysis of the porosity of metals such as magnesium from furnace, in the analysis of the distribution of poorly resistant particles such as sulphur that mechanically act as irregular porosity (Thomas et al., 2013) and polymeric and cementitious mortars (Thomas et al., 2010) comparing the results with other methods to analyse the porosity.

\section{Conclusions}

From the study of the micro and macro-porosity of dry- and saturated-state recycled aggregate concrete, the following conclusions can be obtained.

Total porosity obtained by XCT increases with the substitution ratio, due to the adhered mortar of the aggregate, in a different way for saturated and dry aggregate condition. Porosity increase is higher for the saturated than the dry recycled aggregate. In the first case, the water incorporated by adsorption increases the water/cement ratio reducing mechanical properties. Number and larger pores are observed in the recycled aggregate concrete made with saturated recycled aggregate. Open microstructure is observed when saturated aggregate are incorporated.

The IMA software has been used successfully in recycled aggregate concrete's macroporosity analysis. Results show that the macropore density increases in specimens' height and an exponential tendency of the number of pores with their size is observed, and the increase of the number of small pores is much higher. Larger pores in the perimeter of the sample are observed, increasing with the substitution ratio.

Finally, the use of saturated recycled aggregate would reduce the effects produced by high absorption. However, complete saturation without incorporating extra water by adsorption is difficult and it is also a technically complex process at large scale. It is recommended, therefore, to incorporate extra water during mixing, although the amount should be pre-tested in laboratory.

\section{Downloading the IMA software}

The authors wish to make available to the readers of the journal the code of the program (IMA) for non-commercial use by citing the source. The software code runs in Matlab@ and can be downloaded from https://www.ladicim.es/IMA.zip. For any further support, the reader can contact the authors by emailing the corresponding author.

\section{Acknowledgments}

The authors would like to thank to the José Castillejo Program, founded by the Ministry of Science, Innovation and Universities of Spain, for the research stay of Carlos Thomas at the CERIS, Instituto Superior Técnico of the University of Lisbon, Portugal. To the LADICIM, Laboratory of Materials Science and Engineering of the University of Cantabria and Instituto Superior Técnico of the University of Lisbon for making available to the authors the facilities used in this research.

\section{References}

Angelin, A.F., da Silva, F.M., Barbosa, L.A.G., Lintz, R.C.C., De Carvalho, M.A.G., Franco, R.A.S., 2017. Voids identification in rubberized mortar digital images using K-Means and Watershed algorithms. J. Clean. Prod., Vol. 164, pp: 455-464

Thomas, C. Cimentada, A., Polanco, J.A., Setién, J., Méndez, D., Rico, J., 2013. Influence of recycled aggregates containing sulphur on properties of recycled aggregate mortar and concrete. Comp. Part B: Eng., Vol. 45(1), pp: 474-485 
Thomas, C., Setién, J., Polanco, J.A., Lombillo, I., Cimentada, A., 2014. Fatigue limit of recycled aggregate concrete. Constr. Build. Mater., Vol. 52, pp: 146-154

Choi, W.-., Yun, H.-., 2012. Compressive behavior of reinforced concrete columns with recycled aggregate under uniaxial loading. Eng. Struct., Vol. 41, pp: 285-293

EN 12390-3, 2009. Testing hardened concrete - Part 3: Compressive strength of test specimens

EN 12390-4, 2001. Testing hardened concrete - Part 4: Compressive strength - Specification for testing machines

EN-12390-7, 2009. Testing hardened concrete - Part 7: Density of hardened concrete

F. Rodrigues, M.T. Carvalho, L. Evangelista, J. de Brito, 2013. Physical-chemical and mineralogical characterization of fine aggregates from construction and demolition waste recycling plants. J. Clean. Prod., Vol. 52, pp: 438-445

Fathifazl, G., Abbas, A., Razaqpur, A.G., Isgor, O.B., Fournier, B., Foo, S., 2009. New mixture proportioning method for concrete made with coarse recycled concrete aggregate. J. Mater. Civ. Eng., Vol. 21(10), pp: 601-611

Fathifazl, G., Ghani Razaqpur, A., Burkan Isgor, O., Abbas, A., Fournier, B., Foo, S., 2011. Creep and drying shrinkage characteristics of concrete produced with coarse recycled concrete aggregate. Cem. Concr. Compos., Vol. 33(10), pp: 1026-1037

Fiol, F., Thomas, C., Muñoz, C., Ortega-López, V., Manso, J.M., 2018. The influence of recycled aggregates from precast elements on the mechanical properties of structural self-compacting concrete. Constr. Build. Mater. Vol. 152, pp: 309-323

Guo, Z., Tu, A., Chen, C., Lehman, D.E., 2018. Mechanical properties, durability, and life-cycle assessment of concrete building blocks incorporating recycled concrete aggregates. J. Clean. Prod. Vol. 199, pp: 136-149

$\mathrm{Hu}$, J., 2004. Porosity of Concrete: Morphological study of model concrete. OPTIMA Grafische Communicatie ISBN 90-77595-99-6

Jiménez, C., Barra, M., Valls, S., Aponte, D., Vázquez, E., 2014. Durability of recycled aggregate concrete designed with the Equivalent Mortar Volume (EMV) method: Validation under the Spanish context and its adaptation to Bolomey methodology. Mater. Constr., Vol. 64

Juan-Valdés, A., Rodríguez-Robles, D., García-González, J., Guerra-Romero, M.I., Morán-del Pozo, J.M., 2018. Mechanical and microstructural characterization of non-structural precast concrete made with recycled mixed ceramic aggregates from construction and demolition wastes. J. Clean. Prod., Vol. 180, pp: 482-493

Koenders, E.A.B., Pepe, M., Martinelli, E., 2014. Compressive strength and hydration processes of concrete with recycled aggregates. Cem. Concr. Res. Vol. 56, pp: 203-212

Kong, D., 2003. Unified Bolomey's formula of concrete made with natural and recycled coarse aggregate (I) - Effect of strength of coarse aggregate. Jianzhu Cailiao Xuebao., Vol. 6(2), pp: 129138.

Metha, P., 1986. Concrete: Structure, Properties and Materials. ISBN-13: 978-0131671157

Evangelista, L., de Brito, J., 2007. Mechanical behaviour of concrete made with fine recycled concrete aggregates. Cem. Concr. Compos., Vol. 29(5), pp: 397-401

Lange, D.A., Jennings, H.M., Shah, S.P., 1994. Image analysis techniques for characterization of pore structure of cement-based materials. Cem. Concr. Res., Vol. 24(5), pp: 841-853 
Lei, B., Li, W., Tang, Z., Tam, V.W.Y., Sun, Z., 2018. Durability of recycled aggregate concrete under coupling mechanical loading and freeze-thaw cycle in salt-solution. Constr. Build. Mater., Vol. 163, pp: 840-849

Li, W., Long, C., Tam, V.W.Y., Poon, C., Hui Duan, W., 2017. Effects of nano-particles on failure process and microstructural properties of recycled aggregate concrete. Constr. Build. Mater., Vol. 142(supplement C), pp: 42-50

Li, W., Luo, Z., Sun, Z., Hu, Y., Duan, W.H., 2018. Numerical modelling of plastic-damage response and crack propagation in RAC under uniaxial loading. Mag. Concrete Res., Vol. 70(9), pp: 459472

Li, W., Xiao, J., Sun, Z., Kawashima, S., Shah, S.P., 2012. Interfacial transition zones in recycled aggregate concrete with different mixing approaches. Constr. Build. Mater., Vol. 35, pp:10451055

Martín-Morales, M., Zamorano, M., Ruiz-Moyano, A., Valverde-Espinosa, I., 2011. Characterization of recycled aggregates construction and demolition waste for concrete production following the Spanish Structural Concrete Code EHE-08. Constr. Build. Mater., Vol. 25(2), pp: 742-748

de Juan, M.S., Gutiérrez, P.A., 2009. Study on the influence of attached mortar content on the properties of recycled concrete aggregate. Constr. Build. Mater., Vol. 23(2), pp: 872-877

Medina, C., Sánchez de Rojas, M.I., Thomas, C., Polanco, J.A., Frías, M., 2016. Durability of recycled concrete made with recycled ceramic sanitary ware aggregate. Inter-indicator relationships. Constr. Build. Mater., Vol. 105, pp:480-486

Ministerio de Fomento - Gobierno de España, 2008. EHE-08: Instrucción de Hormigón Estructural

Moretti, J.P., Sales, A., Quarcioni, V.A., Silva, D.C.B., Oliveira, M.C.B., Pinto, N.S., Ramos, L.W.S.L., 2018. Pore size distribution of mortars produced with agroindustrial waste. J. Clean. Prod., Vol 187, pp: 473-484

Pepe, M., Koenders, E.A.B., Faella, C., Martinelli, E., 2014. Structural concrete made with recycled aggregates: Hydration process and compressive strength models. Mech. Res. Commun., Vol. 58, pp: 139-145

Pepe, M., Toledo Filho, R.D., Koenders, E.A.B., Martinelli, E., 2016. A novel mix design methodology for Recycled Aggregate Concrete. Constr. Build. Mater., Vol. 122, pp: 362-372

Sabai, M.M., Cox, M.G.D.M., Mato, R.R., Egmond, E.L.C., Lichtenberg, J.J.N., 2013. Concrete block production from construction and demolition waste in Tanzania. Resour. Conserv. Recycl., Vol. 72, pp: 9-19

Sagoe-Crentsil, K.K., Brown, T., Taylor, A.H., 2001. Performance of concrete made with commercially produced coarse recycled concrete aggregate. Cem. Concr. Res., Vol. 31(5), pp: 707-712

Silva, R.V., de Brito, J., Dhir, R.K., 2016. Establishing a relationship between modulus of elasticity and compressive strength of recycled aggregate concrete. J. Clean. Prod., Vol. 112, pp: 2171-2186

Thomas, C., Setién, J., Polanco, J.A., Alaejos, P., de Juan, M.S., 2013. Durability of recycled aggregate concrete. Constr. Build. Mater., Vol. 40(0), pp: 1054-1065

Thomas, C., de Brito, J., Gil, V., Sainz-Aja, J.A., Cimentada, A., 2018. Multiple recycled aggregate properties analysed by X-ray microtomography. Constr. Build. Mater., Vol. 166, pp: 171-180

Thomas, C., Lombillo, I., Polanco, J.A., Villegas, L., Setién, J., Biezma, M.V., 2010. Polymeric and cementitious mortars for the reconstruction of natural stone structures exposed to marine environments. Compos. Part B, Eng., Vol. 41(8), pp: 663-672 
Thomas, C., Setién, J., Polanco, J.A., 2016. Structural recycled aggregate concrete made with precast wastes. Constr. Build. Mater., Vol. 144, pp: 536-546

Valdés, G.A., Rapimán, J.G., 2007. Physical and mechanical properties of concrete bricks produced with recycled aggregates. Inf. Tecnol., Vol. 18(3), pp: 81-88

Yang, K., Chung, H., Ashour, A.F., 2008. Influence of type and replacement level of recycled aggregates on concrete properties. ACI Mater. J., Vol. 105(3), 289-296

Zhang, Y., He, S., Zhang, X., Liu, X., Lu, W., 2012. Modification of the Bolomey formula in recycled aggregate concrete. Jianzhu Cailiao Xuebao., Vol. 15(4), pp. 538-543. 